\title{
Water Storage Capacity of Contour Furrows in Montana
}

\section{EARL L. NEFF}

Highlight: $A$ field study in eastern Montana related water storage capacity of contour furrows constructed by Model B furrowing machines to furrow age. New contour furrows have a water storage capacity of nearly 1 inch, but this decreases with time owing to natural weathering, intrafurrow dam failure, and furrow breaching. Contour furrows have an average effective life of 25 years, but this ranges from less than 20 years to more than 35 years, depending on initial construction. A new furrowing machine design is suggested that would leave intrafurrow dams of undisturbed soil material, resulting in furrows with either the same storage capacity but at a greatly reduced cost per acre, or over twice the storage capacity at about the same cost per acre as furrows built by a Model B machine.

Mechanical land treatments have been applied to western rangelands for many years to reduce surface runoff, reduce sediment production, and increase desirable forage. These

The author is research hydraulic engineer, U.S. Department of Agriculture, Sidney, Montana.

The study is a contribution from the Soil, Water, and Air Sciences, Western Region, Agricultural Research Service, U.S. Dep. Agr., in cooperation with the Bureau of Land Management, U.S. Department of the Interior, and the Montana Agricultural Experiment Station, Journal Series No. 328.

Manuscript received September 13, 1972. treatments provide surface water storage, which increases infiltration time and results in more soil water storage for plant use. Branson, et al. (1966) published a comprehensive literature review and results of mechanical treatment effects on rangeland in Wyoming, Montana, Colorado, New Mexico, Utah, and Arizona. They point out: "Although mechanical treatments have becn applied extensively, relatively few published reports contain quantitative data on the results of such treatments." The investigation reported here was conducted in Montana to assess contour furrow water storage capacity and longevity.

Contour furrowing is the most common mechanical treatment applied to Montana rangelands on the public domain. While several different designs of furrowing machines have been used in the past, in more recent years the Model B contour furrower developed under the sponsorship of the Range Seeding Equipment Committee by the Equipment Development Center, U.S. Department of Agriculture, Forest Service, San Dimas, Calif., has been used almost exclusively. The Model B contour furrower constructs two furrows 6 to 10 inches deep and 20 to 25 inches wide on 5 -foot centers. A ripper tooth precedes the furrowing discs and rips the soil 10 to 14 inches deep, and a dam-building device can be adjusted 
to construct dams within the furrows at any interval between 5 and 170 feet. Furrows sampled in this study had intrafurrow dams about every 15 feet.

In this study, a furrow was considered to be a furrow section between two intrafurrow dams. A failure occurred when either one of the dams failed, allowing water to drain into the adjacent furrow section, or the furrow itself was breached. In either case, failures usually progressed like toppling dominoes as the drainage from upslope failures exceeded the downslope storage capacity.

\section{Procedure}

Sample furrows were measured at five locations in Carter County, Montana-15 to 20 miles south of Ekalaka-and at two locations in Phillips County, Montana-one 15 miles and another 55 miles southwest of Malta. All locations were on panspot range sites. Furrow age ranged from 6 months to 11 years, and all were constructed by a Model B furrowing machine.

A series of measurements were made within the samples to determine furrow geometry. In general, furrows had trapezoidal cross sections, bottom widths that averaged 12 inches, and were on $5-\mathrm{ft}$ centers. In computations of furrow storage capacity, it was assumed that all furrows conformed to these sample measurements. From this assumption, the volume available for storage is found by:

$$
\text { Furrow volume }=\left[\frac{W+12}{2}\right](d)(L)
$$

where $W$ is furrow width at minimum depth, $d$ is furrow minimum depth, and $L$ is furrow length. This volume is equal to some depth of precipitation falling directly into the furrow or:

$$
\text { Precipitation volume }=(W)(P)(L)=\text { furrow volume }
$$

where $P$ is precipitation depth. Therefore:

$$
(W)(P)(L)=\left[\frac{W+12}{2}\right](d)(L)
$$

and

$$
P=\frac{(W+12) d}{2 W}=S_{s}, \text { the furrow storage capacity }
$$

From the assumption that furrows were on 5 -ft centers, the storage provided for the entire area was found by:

$$
S=S_{s}\left[\frac{W}{60}\right]
$$

where $S$ is area surface water storage. Inches were used as the unit of measurement in all cases.

A random walk technique was used to provide random sampling in furrowed areas. Four walks were generated using tables of random numbers, and each walk resulted in 50 samples in a 20 - to 25 -acre sampling area. Twenty-five random walks were made at the seven locations for an average of about three walks per location. Minimum depth and furrow width at minimum depth were measured at each sampling point. Storage at each point was computed using equations (2) and (4) assuming that furrow mean width was equal to the measured width at minimum depth. The individual points within each walk were averaged, and this average was considered to be a location sample. Furrows measured in the random walks were considered nonfunctional with zero storage if either the intrafurrow dams had failed or the furrow had been breached.

A rational approach was used to develop a mathematical relationship between the dependent variable, furrow storage, and the independent variables, furrow age and percentage of furrows that were effective. First, by definition, $m=$ total number of furrows in an area; $n=$ total number of effective furrows; $t=$ age of furrows in years; $n=n_{O}$ at $t=0$; and $\bar{s}=$ mean storage per effective furrow. Then,

$$
\bar{s}=\frac{\sum_{i} S_{i}}{n}
$$

where $S_{i}=$ storage in furrow $i$. Also, total storage per unit area $S$, at any time is given by:

$$
S=\frac{n \bar{s}}{m}
$$

The rate of change in the number of effective furrows with time is given by the differential equation:

$$
\frac{d n}{d t}=-\rho n
$$

where $\rho$ is the probability of failure of any furrow. Integrating (7) gives:

$$
\ln n=-\rho t+c
$$

or

$$
n=e^{-(\rho t+c)}=e^{-\rho t} e^{c}
$$

where $c$ is some integration constant. But when $t=0, n=e c=$ $n_{O}$ by definition above. Substituting $n_{O}$ for $e^{c}$ in (9) gives:

$$
n=n_{O} e^{-\rho t}
$$

The rate of change of storage in effective furrows with time is given by the differential equation:

$$
\frac{d \bar{s}}{d t}=-\alpha \bar{s}
$$

where $\alpha$ is a decay constant. Integrating (11) gives:

$$
\ln \bar{s}=\alpha t+c
$$

or

$$
\bar{s}=e^{-\alpha t+c}=e^{-\alpha t} e^{c}
$$

But when $t=0, \bar{s}=e^{c}=\bar{s}_{O}$ the initial storage. Substituting $\bar{s}_{O}$ in (13) gives:

$$
\bar{s}=\bar{s}_{O} e^{-\alpha t}
$$

But $\bar{s}=S \frac{m}{n}$ from (6), which when substituted into (14) gives:

$$
S=\bar{s}_{O}\left[\frac{n}{m}\right] e^{-\alpha t}
$$

Substituting (10) into (15) gives:

$$
S=\bar{s}_{o} \frac{n_{O}}{m} e^{-(\alpha+\rho) t}
$$

If $\frac{n}{m}$ is symbolized by $F$ and $\frac{n_{O}}{m}$ by $F_{O}$, then (15) can take the natural log form:

$$
\ln \frac{S}{F}=\ln \bar{s}_{O}-\alpha t
$$

and (16) can take the form:

$$
\ln S=\ln \left(\bar{s}_{O} F_{O}\right)-(\alpha+\rho) t
$$

Linear regression equations have the form:

$$
Y=a+b X
$$

where $Y=$ the dependent variable; $a=Y$ intercept when $X=0$; $b=$ slope of the regression line; and $X=$ the independent variable. If a regression of $\ln \frac{S}{F}$ versus $t$ is made, then from $a=\ln \bar{s}_{O}$ and $b=\alpha$. Also, if a regression of $\ln S$ versus $t$ is made, then from (18) $a=\ln \left(\bar{s}_{O} F_{O}\right)$ and $b=\alpha+\rho$. Regressions were made of data from the field samples and resulted in:

$$
\begin{aligned}
\ln \tilde{s}_{O} & =-0.003 & \alpha & =0.082 \\
\tilde{s}_{O} & =0.997 & \ln \left(\bar{s}_{O} F_{O}\right) & =0.089 \\
\bar{s}_{O} F_{O} & =0.915 & \alpha+\rho & =0.108
\end{aligned}
$$


Substituting (19) into (21):

$$
\begin{aligned}
0.997 F_{O} & =0.915 \\
F_{O} & =0.92
\end{aligned}
$$

Substituting (20) into (22):

$$
\begin{aligned}
0.082+\rho & =0.108 \\
\rho & =0.026
\end{aligned}
$$

\section{Discussion}

In theory, new contour furrows constructed by a Model B furrowing machine should average 8 inches deep, 23 inches wide, and provide almost 2.5 inches of water storage. However, the data reported here do not substantiate this much storage. From equation (6), the initial storage can be found by:

$$
S_{O}=F_{O} \bar{s}_{O}=(0.92)(0.997)=0.92 \text { inch }
$$

which is only $38 \%$ of the theoretical amount. This discrepancy is due to the difference between theoretical furrow depth and the depth actually constructed. Montana field data showed that furrows 6 months old averaged 3.7 inches deep and 20.6 inches wide. Observations indicate that these depths shallower than theoretical are caused by any one or a combination of three reasons: (1) Intrafurrow dams are constructed of loose, unconsolidated soil which, upon wetting and soaking, compact to one-half or less their original height; (2) Adverse soil structural or soil water conditions prevent the furrowing machine from digging to design depth; (3) Furrows are not constructed on the contour because of either rolling topography or improper machine operation. In either case, furrows built with a slope rapidly lose storage due to the domino effect of failures.

By far the most common cause of furrow storage loss is the settling of intrafurrow dams. When dams settle to less than one-half their original height, the minimum depth- $(d$ in equation (3)-is reduced from the total furrow depth of 8 inches to the settled dam height. This, in turn, reduces the average initial water storage capacity of furrowed areas from 2.5 inches to 0.92 inch.

The problem with dams suggests a furrowing machine could be designed to provide intrafurrow dams of compacted material less subject to settling and erosion failures. A machine designed to lift the furrowing discs from the furrows at 15 - to 20 - $\mathrm{ft}$ intervals and leave furrow sections separated by 2 to $3 \mathrm{ft}$ of undisturbed soil would result in furrows that were structurally stable and less subject to intrafurrow dam failure. Such furrows would have more than double the initial water storage capacity of furrows constructed by a Model B machine, because dams of undisturbed material would provide water storage to the full depth of the furrow. This increased water storage should also increase furrow stability because the dams would be overtopped less frequently and, when overtopped, the consolidated and vegetated material would be less subject to erosion. This can be demonstrated by equation (16). If it is assumed that $s_{O}=2.5$ inches, that $\rho$ is reduced by half to 0.013 , that $F_{O}$ remains at 0.92 , and that $\alpha$ remains at 0.032 , then equation (16) can be written:

$$
S=(2.5)(0.92) e^{-0.095 t}
$$

From this, when $t=0, S_{0}=2.3$ inches; when $t=10$ years, $S_{10}=0.89$; when $t=20$ years, $S_{20}=0.38$; and when $t=30$ years, $S_{30}=0.13 \mathrm{inch}$. These estimates compare with estimates for the present Model B furrows of $S_{0}=0.92, S_{10}=0.31$,
$S_{20}=0.10$, and $S_{30}=0.03$ inch.

Since the Model B machine constructs furrows with an average water storage capacity of 0.92 inch, it might be assumed that this storage amount is adequate for rangeland treatment. If this is the case, a machine designed to eliminate the dam settling problem could provide about 1 inch of storage by constructing furrows 4 inches deep and 20 inches wide. In this situation, equation (16) gives: $S_{0}=0.98$, $S_{10}=0.38, S_{20}=0.16$, and $S_{30}=0.06$. Such a furrowing machine would have a much smaller draft requirement than Model B machines, which are pulled by tractors with power equivalent to a Caterpillar D-7 or D-8. A machine pulled by an ordinary farm tractor could construct furrows for about $\$ 12$ per acre, as compared to the estimated $\$ 15$ to $\$ 20$ per acre for furrows constructed by Model B machines.

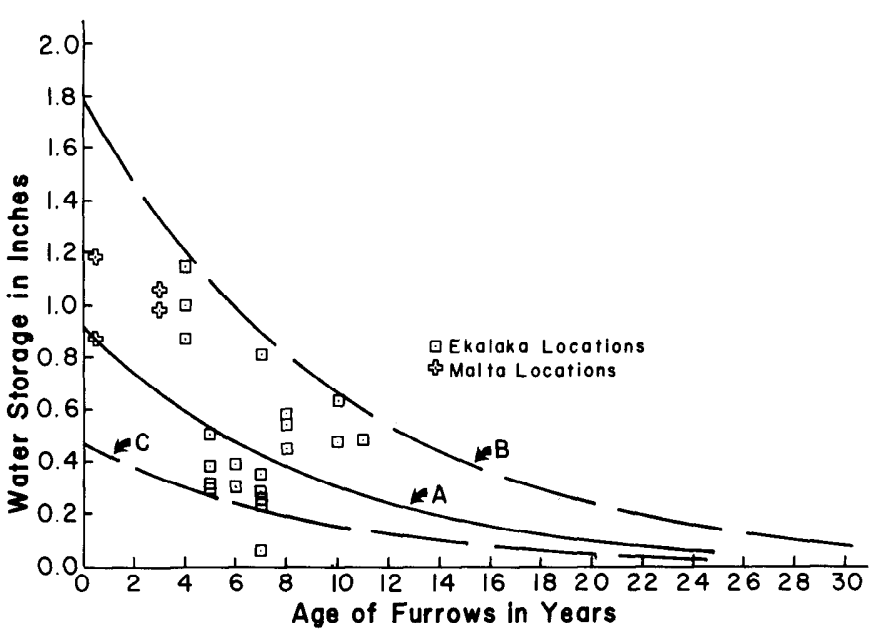

Fig. 1. Water storage versus age of furrows.

Furrow longevity is difficult to assess, but some inferences can be drawn from statistical analysis of the Montana field data. Figure 1 is a plotting of water storage capacity versus furrow age. Curve $A$ is the regression line of $\ln S$ versus age, and curves $B$ and $C$ are the regression line plus and minus one standard deviation, respectively. These curves are interpreted to indicate that for any given age, curve $A$ is the statistically most probable value for storage, and there is a $67 \%$ chance that the true value lies between curve $B$ and $C$. Also, there is a $16-2 / 3 \%$ chance that the true value will be greater than curve $B$ and a corresponding $16-2 / 3 \%$ chance that it will be less than curve $C$. If an arbitrary criterion is established that furrows remain effective only as long as they provide 0.05 inch of water storage, Figure 1 indicates that, on the average, (curve $A$ ) furrows remain effective for about 25 years. However, about one-sixth of all furrow projects will be effective for less than 20 years and one-sixth will remain effective longer than 35 years.

Effective life, as used here, refers only to the water storage capacity. Longevity of another furrowing objective, increasing desirable forage, is beyond the scope of this study. However, if proper grazing practices are followed, the effect on forage should be sustained longer than the effect on surface water storage, due to vegetation establishment and soil physical and chemical changes brought about by contour furrowing. 


\section{Summary}

Contour furrowing is an effective method of increasing water storage on rangelands in Montana. New furrows constructed by a Model B furrowing machine have an average storage capacity of nearly 1 inch. Storage decreases with time and is dependent not only on age but also on initial construction conditions and on the probability of individual furrow failure as expressed by:

$$
S=\bar{s}_{O} F_{O} e^{-(\alpha+\rho) t}
$$

On the average, contour furrows will have an effective life ( $S>0.05$ inch) of 25 years, but there is a one-sixth chance that effective life will be less than 20 years or more than 35 years.
A furrowing machine designed in such a way that furrow sections are separated by compacted or undisturbed soil would provide furrows that either (a) had initial water storage capacity more than twice that of furrows constructed by Model B machines, or (b) had the same storage capacity as those built by a Model B machine, but at a much smaller cost per acre. In either case, storage loss due to intrafurrow dam failures would be greatly reduced, resulting in longer effective life.

\section{Literature Cited}

Branson, F. A., R. F. Miller, and I. S. McQueen. 1966. Contour furrowing, pitting, and ripping on rangelands of the western United States. J. Range Manage. 19:182-190.

\title{
믐ㅁ
}

\section{Second Call for Papers}

\author{
27th Annual Meeting, SRM \\ February 3- 8, 1974, Tucson, Arizona
}

The objective of the Program Committee for the 1974 Annual Meeting is a stimulating program of important topics which will provide something of value and interest to all those who attend. To accomplish this objective, the format for the meeting will include both invited and volunteer papers; it will also provide a forum for examining controversial issues and for the expression of ideas. The committee solicits members and nonmembers to volunteer papers reporting their work, their research, and their ideas. Although papers on any subject relevant to range science and range management, or the affairs of the Society, will be considered, papers representing new knowledge and fresh ideas are especially encouraged. A session of volunteer papers titled "Viewpoints" is being arranged to accommodate those wishing to express their particular viewpoint orally to the Society.

The Program Committee will carefully screen all volunteer papers and select only those that provide reasonable assurance of meeting the high standards of quality that the Society expects. The committee will attempt to accommodate papers on any subject matter.

Procedure-Those wishing to present papers at the 27th Annual Meeting should consider only topics that can be presented with an allocated time of 15 minutes. They should provide the following: (1) title of paper, (2) name and affiliation of author(s), (3) name of individual who will present the paper, (4) name and address of author to whom correspondence should be addressed, (5) a preliminary abstract of not less than 250 nor more than 500 words, and (6) a supporting statement indicating the significance of the offered paper and the subject matter area(s) under which the author thinks the paper should be classified. For research papers, this statement should also indicate the relative amount of data supporting the paper (e.g., years of study, etc.). All illustrative material must be in the form of $2 \times 2$-inch slides for use in Carousel projectors.

Deadlines-Three (3) copies of the preliminary abstract and supporting statement must be in the hands of the Program Committee chairman not later than August 15, 1973 (October 5 for student papers). Authors will be notified of acceptance or rejection of their paper by October 1, 1973 (November 1 for student papers). Final abstracts for all papers must not exceed 300 words and must be received by the Program Committee by November $15,1973$.

Abstracts, inquiries, and correspondence relevant to the program should be addressed to: James $\mathbf{0}$. Klemmedson, Chairman, SRM Program Committee, Department of Watershed Management, University of Arizona, Tucson, Arizona 85721. 